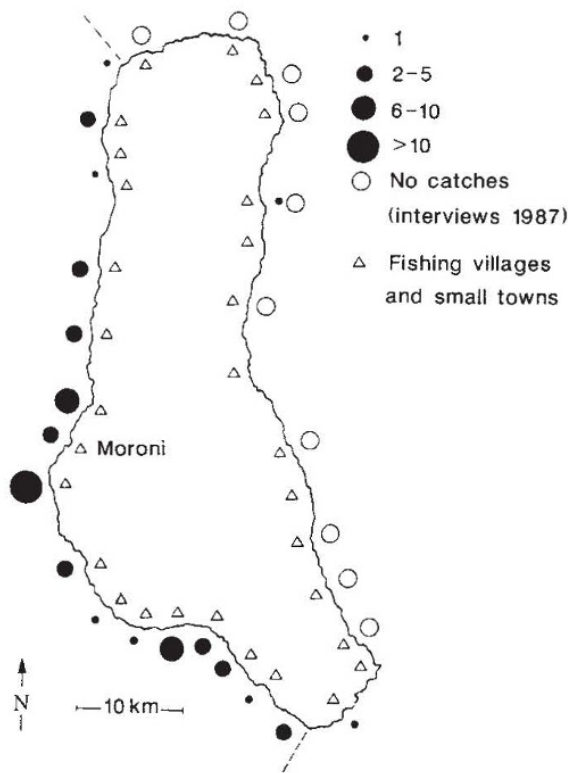

Map of Grande Comore (capital Moroni) with locations of coelacanth catches (filled circles) and distribution of coastal fishing villages and small towns (open triangles). The west coast between Mitsamiouli and Chamboini (dotted lines) is the coelacanth habitat.

of the late president of the Comores. In October 1989, coelacanths were upgraded to schedule 1 of the conservation charter CITES. This might ensure that future generations can rejoice in these gentle and peaceful survivors of our own vertebrate history.

HANS FRICKE KAREN HISSMANN

\section{Max Planck Institut für \\ Verhaltensphysiologie, \\ D8130 Seewiesen, FRG}

1. Bruton, M.N. Trans R. Soc. S. Afr. 47, Part 1. 19-28 (1989).

2. Millot, J., Anthony, J. \& Robineau, D. Bull. Mus. nat. Hist. nat. Zool. 39. 533-548 (1972).

3. Hughes, G.M. \& Itazawa, Y. Experientia 28, 1247 (1972).

\section{Improving PCR efficiency}

SIR-The polymerase chain reaction $(\mathrm{PCR})$ is a very sensitive in vitro DNA amplification method'. Therefore, carryover of even minute quantities of reaction products can lead to serious contamination problems and false-positive results. Tidiness and adherence to a strict set of protocols can avoid disaster ${ }^{2.3}$. Methods

used the amplification of a 275-base pair fragment of the elt gene of enterotoxigenic Escherichia coli ATCC 37218 (ref. 5). We added $5-50,000$ lysed bacterial cells to individual reaction mixtures (excluding Taq DNA polymerase), followed by 0.5 units of DNaseI or 10 units of MspI. After incubation and subsequent inactivation of

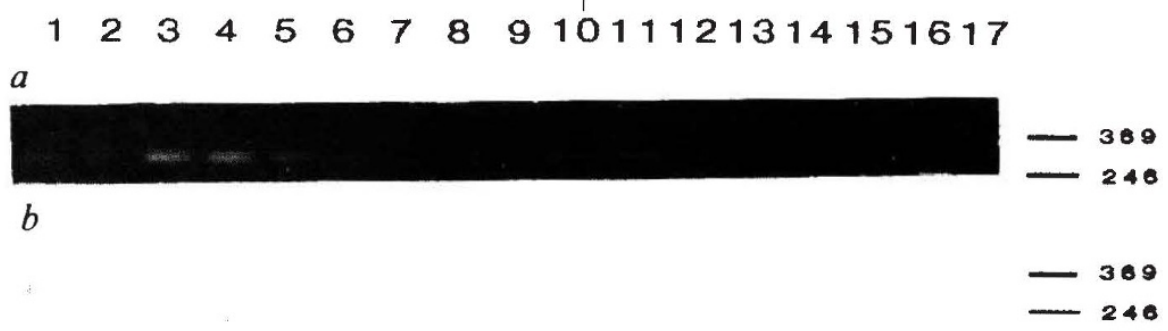

Decontamination efficiency of DNasel or Msp/treatment in PCR. (See ref. 5 for standard methods.) Reaction mixtures (excluding Taq DNA polymerase) which contained lysed bacteria as artificial contaminations were treated with $0.5 \mathrm{U}$ DNase I for $30 \mathrm{~min}$ at room temperature or with $10 \mathrm{U} \mathrm{Msp} /$ for $1 \mathrm{~h}$. After incubation, enzymes were inactivated by boiling, Taq DNA polymerase added and 35 cycles of PCR performed. a, ethidium bromide-stained $1.5 \%$ agarose gel; $b$. Southern blot of $10 \mu \mathrm{l} \mathrm{PCR}$ product. Lanes: $1,50 \mathrm{E}$. coliATCC 37218 , no DNasel or Msp/ treatment of reaction mixture; 2, reaction mixture $M s p /$ treated before adding 50 bacteria; $3-9$, contamination of reaction mixture with $50,000,5,000,500,50,10,5$ and 0 bacteria, respectively, Msp! treatment; 10 , reaction mixture DNase I treated before adding 50 bacteria; $11-17$ contamination of mixture with $50,000,5,000,500,50,10,5$ and 0 bacteria, respectively, DNase I treatment.

which eliminate contamination by PCR products from previous amplifications are indispensable, especially for diagnostic applications. As recently reported in Scientific Correspondence ${ }^{+}$, such contaminations can be eliminated from reaction mixtures by ultraviolet treatment before addition of target DNA.

We have developed an alternative method in which treatment of individual reaction mixtures before adding template DNA and Taq DNA polymerase with DNaseI or restriction endonucleases that cut internal to the pair of amplification primers prevent amplification of contaminating DNA. As a model system, we

\title{
Too soon for consensus?
}

SIR-Crumpton and Dedman in their Scientific Correspondence (Nature 345, 212 ; 1990) proposed a common nomenclature system for a group of proteins presently referred to as lipocortins, annexins, calpactins and so on. Several of us, including those who first identified, isolated and cloned several members of this family, do not agree fully with these changes.

We have no objection to the use of the general designation of annexin to describe the group. But because there is no clear, universally accepted function for any of the proteins we believe that a new nomenclature is premature. Because each family member probably has a specifically tailored function, we suggest, at least in the interim, that a common universally accepted name for each protein (calpactin, endonexin and so on) would simplify matters.

One member of this family has been termed lipocortin-1 in most papers pub- lished over the past 2 years. The name lipocortin is already a result of an attempt to simplify the nomenclature and is reasonably descriptive of the protein's properties. In view of this fact, we feel that it would be an additional burden to impose yet another name - annexin-1.

We would like to make a plea for an open system of nomenclature until more research has shown us the most probable biological roles of this perplexing yet fascinating family of proteins.

\section{J. BROWNING \\ B. PEPINSKY \\ B. WALLNER}

Biogen Inc.,

14 Cambridge Center,

Cambridge, Massachusetts 02142, USA

R. J. FLOWER

S. H. PEERS

Dept of Biochemical Pharmacology,

St Bartholomew's Medical College,

London EC1M 6BQ, UK enzymes, we added Taq DNA polymerase and performed 35 cycles of PCR. As shown in the figure, MspI treatment reduces contamination by a factor of 5 to 10 without impairing the efficiency of the PCR. DNaseI treatment reduces contamination by a factor of 1,000 . Comparison of lanes 1 and 10 shows that the efficiency of PCR is not reduced by this treatment as primers are not significantly attacked by DNaseI under the conditions chosen. The decontamination conditions can easily be optimized together with optimization of PCR components.

The efficiency of restriction-enzyme digestion can be increased by adding more than one enzyme and by increasing the enzyme concentration as well as the incubation time. The sequence specifity of the restriction-enzyme treatment can be circumvented by using a cocktail of enzymes that recognize tetranucleotide target sequences. The main advantage of this method is its general applicability based on the use of DNaseI, a cheap enzyme requiring no sequence information between amplification primers.

B. FURRER

U. CANDRIAN

P. WIELAND

J. LÜTHY

Laboratory of Food Chemistry,

Institute of Biochemistry,

University of Berne, 3012 Berne, Switzerland

1. Saiki, R.K. et al. Science 239, 487-491 (1988).

2. Kwok, S. \& Higuchi, R. Nature 339, 237-238 (1989)

3. Kitchin, P.A.. Szotyori, Z., Fromholc, C. \& Almond, N. Nature 344, 201 (1990).

4. Sarkar, G. \& Sommer, S.S., Nature 343, 27 (1990).

5. Furrer, B., Candrian, U. \& Lüthy, J. Lett. Appl. Microbiol. 10, 31-34 (1990) 